\title{
Reduced Chemistries with the Quantemol Database (QDB)
}

Adetokunbo AYILARAN ${ }^{1}$, Martin HANICINEC ${ }^{2}$, Sebastian MOHR ${ }^{1}$, Jonathan

TENNYSON $^{2}$ *

${ }^{1}$ Quantemol Ltd., 320 City Rd, London EC1V 2NZ, United Kingdom

${ }^{2}$ Department of Physics and Astronomy, University College London, London

WC1E 6BT, United Kingdom

*E-mail address of corresponding author: j.tennyson@ucl.ac.uk

\section{Abstract}

Typical feed gas mixtures used in technological and other plasmas may give rise to reaction networks involving several hundred reactions. Such chemistries are often too large to be used in full reactor simulations and it is therefore desirable to construct reduced chemistry networks which mimic as closely as possible the behavior of the full chemistry but employ far few individual reactions and species. Constructed chemistries are available from the Quantemol Database (QDB) and two approaches for constructing reduced chemistry from these chemistries based on (a) physical intuition and (b) sensitivity analysis of dominant reaction pathways are explored. In doing this it is necessary to consider different pressure and power regimes. Reduced chemistry sets are presented for the $\mathrm{CF}_{4} / \mathrm{O}_{2} / \mathrm{N}_{2} / \mathrm{H}_{2}$, for which 396 reactions and 52 species are reduced to 71 reactions and 26 species, and pure $\mathrm{O}_{2}$, for which 45 reactions and 10 species are reduced to 34 reactions.

Keywords: Plasma chemistries. Quantemol Database, chemical reactions, chemistry reduction, Stoichiometry 


\section{Introduction}

Low temperature plasmas are characterized by having significant molecular content. These plasmas generally undergo a variety of processes via (a) interactions with electrons which can induce chemical change by, for example, neutral dissociation, (b) chemical reactions between species in the plasma or (c) reactions on the walls of the vessel containing the plasma. Below we describe the gas phase processes for a given feed gas as the plasma chemistry. Using these chemistries as the basis of detailed plasma models is becoming an increasingly important activity scientifically [1,2]. As a result databases [3-7] and datasets (for example [8-10]) are being systematically compiled to provide cross sections and rates for processes thought to be important within plasmas. Two of these databases, KIDA [4] and the Quantemol Database (QDB) [7], attempt to augment lists of individual processes by providing comprehensive chemistry sets for plasma environments of interest. In the case of KIDA [4], the kinetic database for astrochemistry, these chemistries, which KIDA terms networks, are designed for studies of the interstellar medium. QDB [7], which is the database that concerns us here, is designed for studies of terrestrial plasmas particularly technological ones used, for example, for silicon etching.

QDB aims not only to provide comprehensive sets of reaction rates and electron 
collision cross sections, but also offers pre-assembled and validated self-consistent chemistry sets for plasma modelling applications. QDB plans to be augmented with a dynamic chemistry facility which automatically constructs a set of key reactions for a given set of gases and chamber conditions. For this, a method of compiling and reducing complex chemistry is necessary.

Those chemistries available in QDB can contain a relatively modest number of reactions, for example 16 for a pure helium plasma, but the chemistry sets more often contain many hundreds of reactions, for example 557 for a chemistry based on the use of a $\mathrm{CF}_{4}, \mathrm{CHF}_{3}, \mathrm{H}_{2}, \mathrm{Cl}_{2}, \mathrm{O}_{2}, \mathrm{HBr}$ mixture. Performing detailed equipment models for key plasma processes requires propagating plasma models for complex reactor geometries over many time steps. Doing this for chemistries containing several hundred reactions is at best computationally demanding and in some cases computationally impossible. Indeed, some well-used software packages, such as COMSOL, experience convergence issues which tend to limit the number of reactions that can be used to about $50[11]$

For this reason, it is desirable to design reduced chemistry sets. These are chemistry sets which approximately mimic the behavior of a simulation performed with the full chemistry, while containing a greatly reduced number of species and reactions. Some work in this direction has recently been performed for astrochemical networks 
appropriate for models of interstellar molecular clouds [12]. However, the lowtemperature, near-vacuum conditions found in the interstellar medium gives a set of conditions not found on Earth. Markosyan et al. [13] presented a tool developed to find dominant reaction pathways which they present as an essential method for chemistry reduction. The tool (called PumpKin) uses the outputs of a zero-dimensional (0D) modeler as inputs where the species concentrations are calculated in steady state and the source term of species production and destruction are calculated from the stoichiometric matrix. This method has strong similarities to the analysis carried in this work. Here we explore construction of reduced chemistry sets for terrestrial applications and, in particular, demonstrate that in most cases there will not be unique reduced chemistry set for all applications but instead it is necessary design different sets according to temperature and pressure regime of the plasma being considered.

\section{Method}

Our aim is to produce reduced chemistry sets with a few tens of reactions starting from complex chemistries containing several hundred reactions. We do this by comparing zero-dimensional models for the complete set and various reduced sets. All the zerodimensional models were performed using $\pi$ lasma-R 0D modelling code of Kokkoris and co-workers $[14,15]$. Monitoring the evolution of the plasma as these parameters are changed involves the use of $0 \mathrm{D}$ modeling code which can comfortably calculate large chemistry sets with the main input being power density and pressure. In particular, 
modeling using rate constant coefficients kept computation time low. In QDB, these rate constant coefficients, $k$, are given in the form of the parameters of the Arrhenius equation:

$$
k=A T_{e}^{B} e^{-\frac{C}{T_{e}}}
$$

Where $T_{e}$ is the electron temperature, and $A, B$ and $C$ are the constants characterizing the reaction and given by the database. Knowledge of these rates coefficients and of the typical behavior of plasmas under the given conditions can be used to remove reactions and species on the basis of physical intuition.

The use of actual modeling gives a numerical reduction procedure which eliminates conjecture about which reactions to remove and instead uses a combination of stoichiometry and sensitivity analysis to determine the participation of certain species and their reactions within the network that defines the chemistry set [16]. For a given network of reactions, a master chemical kinetics equation [17] can be expressed as:

$$
\frac{d y_{i}}{d t}=g\left(y_{i}\right)=\sum_{j=1}^{R} s_{i j} F^{j}\left(y_{i}\right)
$$

Where $i$ and $j$ represent the species number and reaction number respectively; $R$ is the total number of reactions in the network; $s_{i j}$ is a stoichiometric coefficient detailing the participation of a species in a given reaction. $F_{j}$ is the rate of reaction $j$ which depends on $y$, a list of chemical species that form the system, and their concentrations. As this 
analysis assumes the plasma is in steady state, the master chemical kinetics equation is characterized by the rate of change of total concentration (if used globally) or specific species concentration (if used locally for a single species). This method also relies on the conservation of the number of elements and the total mass in a given reaction. The rate of change of concentration in the system is trivialized by applying 'changes' to the system. This can be expressed as a perturbation:

$$
\frac{d y_{i}}{d t}=g\left(y_{i}\right)+\delta g(y)
$$

The perturbation $\delta g(y)$ may represent a reaction missing from the previous calculation of $g\left(y_{i}\right)$, a variation of rate constants (if knowledge of them is uncertain), or any other arbitrary change such as the removal of entire species. Therefore, the identification of dominant pathways that control species concentrations is the primary use of this method whilst sensitivity of these pathways is secondary.

Changing reaction rates or removing reactions/species from the system gives a measure of that change's importance to the system as a whole and manifests itself as a perturbation, $\delta g\left(y_{i}\right)$. The larger the perturbation, the larger is the effect on the system. The effect of the perturbations is classified using a coefficient, $C_{i}$,

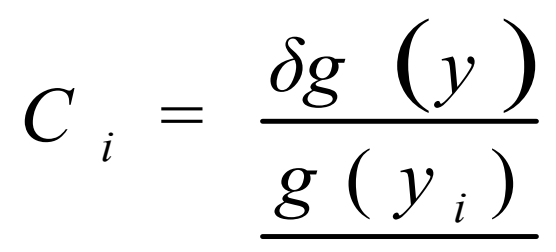

It is often the case that, depending on the pressure, removing a reaction or slightly 
changing its reaction rate will have almost no effect on the system as a whole. This is where the chemistry reduction process takes shape as unimportant reactions with $C_{i} \sim$ 0 are removed, whilst dominant reactions that have a coefficient $\left|C_{i}\right| \geq \varepsilon$ are retained, where $C_{i}$ can typically be as low as $1 \times 10^{-5}$.

This method can be considered superior to using physical intuition to decide which reactions and species to neglect as it can be programmed into an algorithm yielding quantitative results which can used to make informed judgments. This analytical method can be used to define logical steps from a full chemistry set to a reduced one.

In constructing the reduced chemistry set it is necessary to consider a range of physical environments as the reduction is sensitive to the physics that occurs at various pressures and powers and the details of this physics justifies the removal of species and reactions from the chemistry set. The most sensitive parameter is pressure which determines the mean free path of the heavy particles. The reaction rate for heavy particle processes depends on the mean free path as does the electron temperature, $T_{e}$. This means that at high pressures, $T_{e}$ is reduced and electron -- heavy particle collisions favor attachment and dissociation, rather than high energy impact ionization. Furthermore, high pressures enable neutral - neutral collisions to occur on length scales comparable to or less than the reactor vessel dimensions. Very low pressures reduce the chances of neutral -- neutral collisions and most heavy particle collisions are therefore chargeexchange and neutralization. So different reactions dominate in different pressure 
regimes and these regimes can be associated with specific applications. We therefore divide our considerations into the following pressure regimes and example applications:

Very Low pressure: 1 - 30 mTorr; application ion bombardment etching;

Low pressure: 30 - 100 mTorr; application ion etching with some neutral assistance;

Medium pressure: 100 - 500 mTorr; application some ion etching with neutral coverage;

High pressure: 500 - 1000 mTorr, application neutral deposition.

The other parameter that needs to be considered is power. Variation of power has a minimal effect on $T_{e}$ but mainly controls the electron density. Varying the power controls dissociation of the plasma species and the density of charged species in the plasma. A plasma with a high power input or high power density is likely to be very fractionated and electropositive. This is because as the power is raised, the electron density is also raised. The increase in electron density leads to a higher degree if dissociation, i.e. a larger amount of atomic species to molecular species. As negative ions are created by dissociative attachment of molecular species, the density of negative ions decreases as the proportion of atomic species increases. 
3. Examples of practical reduced chemistry

As a working example we use the chemistry arising from a feed gas mixture $\mathrm{CF}_{4} / \mathrm{O}_{2} / \mathrm{N}_{2} / \mathrm{H}_{2}$. This gas mixture, with varying initial plasma conditions, is used in remote plasma chemical etching, direct plasma etching with $\mathrm{CF}_{4} / \mathrm{O}_{2}$ of poly-Si and $\mathrm{SiO}_{2}$ with additions of $\mathrm{N}_{2}$ and $\mathrm{H}_{2}$ depending on the surface of the substrate and dry reactive ion etching in Through Silicon Via (TSV) cleaning [18-20].

Table 1. Details of parameters used in our model of a microwave reactor.

\begin{tabular}{|l|l|}
\hline Property & Value \\
\hline Reactor & Microwave \\
\hline Power Range / W & $0-2000$ \\
\hline Pressure Range / mTorr & $1-1000$ \\
\hline Gas Mixture & $\mathrm{CF}_{4} / \mathrm{O}_{2} / \mathrm{N}_{2} / \mathrm{H}_{2}$ \\
\hline Percentage of Gas / \% & $0.1 / 85 / 14.15 / 0.75$ \\
\hline Total Gas Flow / SCCM & 3780 \\
\hline
\end{tabular}

We carried out $0 \mathrm{D}$ chemistry modelling based upon a reactor and process settings used in a previous $2 \mathrm{D}$ investigation; these are given in Table 1.

The chemistry set for $\mathrm{CF}_{4} / \mathrm{O}_{2} / \mathrm{N}_{2} / \mathrm{H}_{2}$ available from QDB contains 396 reactions, data on which were taken from Refs. [21-29], involving 52 species; this chemistry forms our base set.

\subsection{Physical intuition}

Figure 1 illustrates the effect of increasing the pressure and/or density of the feed gas.

In general as the pressure increases less of the gas is consumed in electron impact 
collisions and gas phase recombination reactions happen more frequently. The discharge becomes more electronegative and this is illustrated by the increase in negative charge density. The electron temperature is notably lowered as the pressure is increases due to the smaller mean free path. There is a point at medium pressure where atomic positive ions are at their highest densities.

\section{Figure 1 here}

Figure 1 Concentrations of species in the plasma as function of initial pressure for a power of $1000 \mathrm{~W}$. (a) electron density and temperature, (b) positive atomic ion density, (c) negative ion density, (d) heavy positive ion density, (e) ionized molecule densities,

(f) neutral molecule densities, (g) neutral radical densities, and (h) feed gas densities

Figure 2 shows the behavior of the plasma a function of initial power. As expected, we observe an increase in electron density and atomic species, most notably atomic positive ions. There is seen to be some noticeable decrease in $\mathrm{NH}_{\mathrm{x}}$ species and this can be attributed to combined mechanisms of dissociation and the fact that the $\mathrm{H}^{-}$ion density gradually decreases which follows on from the lowered electronegativity of the discharge. The increase in dissociation is followed by a visible decrease in feed gas and increase in atomic/feed gas ratio. Because the production of heavy neutral ground state species generally depends on the recombination of radicals, their densities also increase before plateauing. 
Figure 2 here

Figure 2 Concentrations of species in the plasma as function of power at a pressure of 10 mTorr. (a) electron density and temperature, (b) positive atomic ion density, (c) negative ion density, (d) heavy positive ion density, (e) ionized molecule densities, (f) neutral molecule densities, (g) neutral radical densities, and (h) feed gas densities

Initial reduced chemistry sets were constructed using physical intuition for a pressure of 10 mTorr and the power of $1000 \mathrm{~W}$. Physical intuition can allow one to make sweeping assumptions and reduces chemistry based upon the physics of the discharge. The low pressure means that neutral-neutral collisions are rare due to mean free paths which are greater than the system size. There are also effectively no negative heavy ions due the high degree of dissociation. Furthermore, if etching process is required, 10 mTorr partially ensures the anisotropy of energetic ions - although this is generally in combination with high voltage sheaths.

Table 2 Densities and electron energies for the full and reduced set using physical intuition.

\begin{tabular}{|c|c|c|c|}
\hline Species & $\begin{array}{c}\text { Reduced Set } / \\
\mathbf{m}^{-3}\end{array}$ & Full Set $/ \mathbf{~ m}^{-3}$ & Percentage Change \\
\hline $\mathrm{H}_{2}$ & $1.04 \mathrm{E}+18 \mathrm{~m}^{-3}$ & $5.43 \mathrm{E}+17 \mathrm{~m}^{-3}$ & $91.52 \%$ \\
\hline $\mathrm{H}$ & $1.54 \mathrm{E}+18 \mathrm{~m}^{-3}$ & $1.72 \mathrm{E}+18 \mathrm{~m}^{-3}$ & $10.46 \%$ \\
\hline $\mathrm{H}^{+}$ & $2.45 \mathrm{E}+15 \mathrm{~m}^{-3}$ & $4.59 \mathrm{E}+15 \mathrm{~m}^{-3}$ & $46.62 \%$ \\
\hline
\end{tabular}




\begin{tabular}{|c|c|c|c|}
\hline $\mathrm{O}_{2}$ & $1.82 \mathrm{E}+20 \mathrm{~m}^{-3}$ & $1.78 \mathrm{E}+20 \mathrm{~m}^{-3}$ & $2.25 \%$ \\
\hline $\mathrm{O}^{-}$ & $2.72 \mathrm{E}+16 \mathrm{~m}^{-3}$ & $2.64 \mathrm{E}+16 \mathrm{~m}^{-3}$ & $3.03 \%$ \\
\hline $\mathrm{O}$ & $4.09 \mathrm{E}+19 \mathrm{~m}^{-3}$ & $3.70 \mathrm{E}+19 \mathrm{~m}^{-3}$ & $10.54 \%$ \\
\hline $\mathrm{O}_{2}^{+}$ & $2.67 \mathrm{E}+18 \mathrm{~m}^{-3}$ & $2.67 \mathrm{E}+18 \mathrm{~m}^{-3}$ & $0 \%$ \\
\hline $\mathrm{O}^{+}$ & $5.65 \mathrm{E}+17 \mathrm{~m}^{-3}$ & $5.45 \mathrm{E}+17 \mathrm{~m}^{-3}$ & $3.67 \%$ \\
\hline $\mathrm{N}_{2}$ & $3.01 \mathrm{E}+19 \mathrm{~m}^{-3}$ & $2.08 \mathrm{E}+19 \mathrm{~m}^{-3}$ & $30.9 \%$ \\
\hline $\mathrm{N}$ & $7.63 \mathrm{E}+18 \mathrm{~m}^{-3}$ & $1.54 \mathrm{E}+19 \mathrm{~m}^{-3}$ & $50.45 \%$ \\
\hline $\mathrm{N}_{2}{ }^{+}$ & $2.20 \mathrm{E}+17 \mathrm{~m}^{-3}$ & $1.57 \mathrm{E}+17 \mathrm{~m}^{-3}$ & $40.13 \%$ \\
\hline $\mathrm{N}^{+}$ & $3.85 \mathrm{E}+16 \mathrm{~m}^{-3}$ & $7.20 \mathrm{E}+16 \mathrm{~m}^{-3}$ & $46.53 \%$ \\
\hline $\mathrm{CF}_{4}$ & $1.93 \mathrm{E}+17 \mathrm{~m}^{-3}$ & $1.45 \mathrm{E}+17 \mathrm{~m}^{-3}$ & $33.1 \%$ \\
\hline $\mathrm{F}^{-3}$ & $9.67 \mathrm{E}+16 \mathrm{~m}^{-3}$ & $1.50 \mathrm{E}+17 \mathrm{~m}^{-3}$ & $35.53 \%$ \\
\hline $\mathrm{CF}_{3}$ & $1.27 \mathrm{E}+16 \mathrm{~m}^{-3}$ & $4.29 \mathrm{E}+16 \mathrm{~m}^{-3}$ & $70.4 \%$ \\
\hline $\mathrm{CF}_{2}$ & $1.82 \mathrm{E}+16 \mathrm{~m}^{-3}$ & $2.36 \mathrm{E}+16 \mathrm{~m}^{-3}$ & $22.88 \%$ \\
\hline $\mathrm{CF}_{3}{ }^{+}$ & $1.31 \mathrm{E}+15 \mathrm{~m}^{-3}$ & $1.26 \mathrm{E}+15 \mathrm{~m}^{-3}$ & $3.97 \%$ \\
\hline $\mathrm{F}^{+}$ & $2.98 \mathrm{E}+14 \mathrm{~m}^{-3}$ & $4.89 \mathrm{E}+14 \mathrm{~m}^{-3}$ & $39.06 \%$ \\
\hline $\mathrm{CF}_{2}{ }^{+}$ & $3.48 \mathrm{E}+14 \mathrm{~m}^{-3}$ & $5.12 \mathrm{E}+14 \mathrm{~m}^{-3}$ & $32.03 \%$ \\
\hline $\mathrm{CF}^{+}$ & $5.66 \mathrm{E}+14 \mathrm{~m}^{-3}$ & $5.25 \mathrm{E}+14 \mathrm{~m}^{-3}$ & $7.81 \%$ \\
\hline $\mathrm{CF}$ & $1.07 \mathrm{E}+16 \mathrm{~m}^{-3}$ & $7.73 \mathrm{E}+15 \mathrm{~m}^{-3}$ & $38.42 \%$ \\
\hline $\mathrm{T}_{\mathrm{e}}$ & $3.56099 \mathrm{eV}^{-3}$ & $3.60342 \mathrm{eV}^{-3}$ & $1.18 \%$ \\
\hline $\mathrm{n}_{\mathrm{e}}$ & $3.47 \mathrm{E}+18 \mathrm{~m}^{-3}$ & $3.42 \mathrm{E}+18 \mathrm{~m}^{-3}$ & $1.46 \%$ \\
\hline
\end{tabular}

Although some of the percentage changes may look alarming (up to $100 \%$ is actually acceptable as doubling/halving of densities is within an order of magnitude), densities within the same order of magnitude are generally acceptable. For species with very low densities predominantly, it is not uncommon to experience large changes in densities during studies as there is general uncertainty in their measurement, especially when measured experimentally. The biggest changes are seen from the $\mathrm{H}_{2}$ density and this can be attributed to its dissociation being due to $\mathrm{H}$ formation and not other pathways such as $\mathrm{H}_{2}{ }^{+}$and $\mathrm{H}_{3}{ }^{+}$. The removal of these species means that the main loss process of 
$\mathrm{H}_{2}$ is due to its dissociation. The concentration of molecular hydrogen is very small compared to the other feed gases and its density is of the same order as the electron density, hence, the change in density is reasonable even though ionization usually does not change the neutral densities significantly. $\mathrm{CF}_{3}$ similarly has a noticeable change due to the removal of pathways that include the recombination or neutralization of $\mathrm{CF}_{3}^{+}$ and $\mathrm{F}^{+}$, as these species exist in very low concentrations. It is important to be wary of removing such possible intermediate species. In this case, the bulk of the $\mathrm{CF}_{3}$ density comes from the electron impact dissociation of $\mathrm{CF}_{4}$, so other pathways that include $\mathrm{F}^{+}$ and $\mathrm{CF}_{3}{ }^{+}$can be neglected. However, for other species its low density may be because its destruction pathway sustains the density of another species. This can be difficult to see intuitively unless seen beforehand or by using numerical sensitivity analysis.

Table 2 shows results obtained using physical intuition. Using this method the 396 reactions were reduced to 50 key reactions and 21 species. Many of the rates are dominated by the electron density which, as can be seen, does not change significantly. This reduction was done in several steps:

- Choosing a pressure range to examine the participation of certain types of collisions

○ Neutral-neutral collisions

$\circ$ Charge-exchange collisions

○ Charge-neutralization collisions 
- Electron impact ionization collisions

- Electron impact dissociation collisions

- Choosing a power range to examine the dissociation of the plasma

- High power is highly dissociative due to large electron densities and therefore high ionization rates

- Low power is weakly dissociated due to lower electron densities and therefore low ionization rates

The following species where removed from the chemistry along with all the reactions involving them. Anions $\mathrm{O}_{3}^{-}, \mathrm{O}_{2}^{-}$and $\mathrm{CF}_{3}^{-}$as they are heavy negative ions and dissociative processes dominate the plasma; $\mathrm{C}$ and $\mathrm{C}^{+}$was removed as $\mathrm{C}$ and $\mathrm{C}^{+}$ densities remain low due to consecutive recombination and deposition only occurring far from the main power absorption region. $\mathrm{H}_{2} \mathrm{O}, \mathrm{H}_{2} \mathrm{O}^{+}, \mathrm{CO}, \mathrm{CO}^{+}, \mathrm{CN}, \mathrm{HCN}, \mathrm{HCN}^{+}$, $\mathrm{HF}$ and $\mathrm{HF}^{+}$were removed as the ground states are the products of neutral gas-phase collisions which occur very infrequently at a pressure of 10 mTorr and the ionized species are created by charge-exchange of the ground state.

Other species suspected of being of reduced importance included $\mathrm{H}^{-}, \mathrm{F}^{-} \mathrm{O}_{3}, \mathrm{NH}_{2}$, $\mathrm{NH}_{2}{ }^{+}, \mathrm{H}_{2}{ }^{+}, \mathrm{H}_{3}{ }^{+}, \mathrm{NO}, \mathrm{NO}^{+}, \mathrm{F}_{2}{ }^{+}$and $\mathrm{F}_{2}$. These species were removed and new reduced chemistry was again compared with the full set at 10 mTorr. Further species were then removed starting with the anions $\mathrm{H}^{-}$and $\mathrm{F}^{-}$as their concentration was more than 3 orders-of-magnitude lower than the electron density. At this power and pressure, negative charge density is dominated by electrons and only $\mathrm{O}^{-}$ions are noticeable. $\mathrm{O}_{3}$ 
was removed as its dissociation processes are most likely to be dominant and its density becomes negligible below 100 mTorr. $\mathrm{NH}, \mathrm{NH}^{+}, \mathrm{NH}_{2}, \mathrm{NH}_{2}{ }^{+}, \mathrm{NH}_{3}$ and $\mathrm{NH}_{3}{ }^{+}$were all removed due to the removal of $\mathrm{H}^{-}$meaning there was no production of $\mathrm{NH}$ which is necessary for heavier $\mathrm{NH}_{\mathrm{X}}$ formation. $\mathrm{H}_{2}{ }^{+}$and $\mathrm{H}_{3}{ }^{+}$were removed as the high degree of dissociation results in a very high density of $\mathrm{H}$ atoms; if $\mathrm{H}_{2}{ }^{+}$is removed, $\mathrm{H}_{3}{ }^{+}$must also be removed as $\mathrm{H}_{2}+$ is the intermediate to its formation. $\mathrm{F}_{2}$ and $\mathrm{F}_{2}+$ were removed their production appears increase with pressure and therefore is very low at the pressure under consideration.

Regardless of the physical insight, one must be able to demonstrate the validity of removing certain species. Thus, for example, Yang et al. [30] stresses the importance of including $\mathrm{H}^{-}$even at low pressures approaching $7.5 \mathrm{~m}$ Torr in a pure $\mathrm{H}_{2}$ discharge in order to correctly determine the electron density and pressure. The removal of the $\mathrm{NH}_{\mathrm{x}}$ species from our chemistry means that an important loss process for $\mathrm{H}^{+}\left(\mathrm{N}+\mathrm{H}^{+}\right.$ $\rightarrow \mathrm{NH}+\mathrm{e}$ ) is no longer prevalent. As a result, the $\mathrm{H}^{\square}$ density before removal of $\mathrm{NH}$ is $6.85 \times 10^{15} \mathrm{~m}^{-3}$ which is reduced to $5.71 \times 10^{15} \mathrm{~m}^{-3}$ after removal of $\mathrm{NH}$. Losses processes of $\mathrm{H}^{-}$are still overwhelmingly large due to charge-neutralization with $\mathrm{O}_{\mathrm{x}}{ }^{+}$, $\mathrm{N}_{\mathrm{x}}{ }^{+}$and $\mathrm{H}_{\mathrm{x}}{ }^{+}$species. Furthermore, removal of $\mathrm{H}^{-}$from the plasma did not affect the species of $\mathrm{O}_{\mathrm{x}}{ }^{+}, \mathrm{N}_{\mathrm{x}}{ }^{+}$and $\mathrm{H}_{\mathrm{x}}{ }^{+}$. So without it being an important intermediary step and not being particularly important correctly estimating the plasma parameters of electron density and temperature, $\mathrm{H}^{-}$was removed. 


\subsection{Numerical Stoichiometric Analysis}

\subsubsection{Oxygen chemistry}

A simpler example involves an $\mathrm{O}_{2}$ chemistry at high pressure (600 Torr). The reaction set includes 45 gas phase reactions and is reduced to 34 reactions based upon numerical reduction. Due to the smaller size of the chemistry, global analysis was applied and the entire chemistry set was studied in order to eliminate unimportant reaction pathways. This particular chemistry was chosen not just for its smaller size, but because it contains 'exotic' species in the form of $\mathrm{O}_{3}, \mathrm{O}_{2}{ }^{-}$and $\mathrm{O}_{3}{ }^{-}$as well as metastable states which are important intermediaries whilst their concentrations are very much dependent on pressure. The chemistry extracted from QDB is shown in Table 3; data for individual processes were taken from Brian [31], Itikawa [33] and Kossyi et al. [34]

Table 3. Reactions used to construct pure oxygen chemistry in QDB.

\begin{tabular}{|c|c|c|}
\hline Reaction & Mechanism & Rate Coefficient $/ \mathbf{m}^{-6} \mathbf{s}^{-1}$ \\
\hline 1 & $e+O_{2} \rightarrow O^{*}+O+e$ & $5.08 \times 10^{-17} T_{e}{ }^{1.18} e^{-\frac{8.96}{T_{e}}}$ \\
\hline 2 & $e+O_{2} \rightarrow O_{2}{ }^{*}+e$ & $2.40 \times 10^{-14} T_{e}{ }^{0.20} e^{-\frac{7.481}{T_{e}}}$ \\
\hline 3 & $e+O_{2} \rightarrow O^{-}+O$ & $6.74 \times 10^{-16} T_{e}{ }^{-1.02} e^{-\frac{5.78}{T_{e}}}$ \\
\hline 4 & $e+O_{2} \rightarrow O^{+}+O^{-}+{ }^{-1.28} e^{-\frac{7.38}{T_{e}}}$ \\
\hline 5 & $e+O_{2} \rightarrow O_{2}{ }^{+}+e+e$ & $7.08 \times 10^{-15} T_{e}{ }^{0.76} e^{-\frac{13.81}{T_{e}}}$ \\
\hline 6 & $e+O_{2}{ }^{*} \rightarrow O_{2}{ }^{+}+e+e$ & $1.3 \times 10^{-15} T_{e}{ }^{1.1} e^{-\frac{11.1}{T_{e}}}$ \\
\hline
\end{tabular}




\begin{tabular}{|c|c|c|}
\hline 7 & $e+O_{2} \rightarrow O^{+}+O+e+e$ & $9.92 \times 10^{-16} T_{e}^{1.101} e^{-\frac{20.30}{T_{e}}}$ \\
\hline 8 & $e+O_{2}^{+} \rightarrow O+O$ & $1.53 \times 10^{-14} T_{e}^{-0.51} e^{-\frac{0.013}{T_{e}}}$ \\
\hline 9 & $e+O \rightarrow O^{+}+e+e$ & $4.82 \times 10^{-15} T_{e} e^{0.74} e^{-\frac{13.11}{T_{e}}}$ \\
\hline 10 & $e+O^{-} \rightarrow O+e+e$ & $1.95 \times 10^{-18} T_{e}^{-0.5} e^{-\frac{3.4}{T_{e}}}$ \\
\hline 11 & $e+O^{*} \rightarrow O+e$ & $5.82 \times 10^{-15} T_{e}^{-0.20} e^{-\frac{1.08}{T_{e}}}$ \\
\hline 12 & $e+O^{*} \rightarrow O^{+}+e+e$ & $1.56 \times 10^{-14} T_{e}^{0.29} e^{-\frac{13.30}{T_{e}}}$ \\
\hline 13 & $e+O_{3} \rightarrow O_{2}+O^{-}$ & $1.87 \times 10^{-15} T_{e}^{-1.30} e^{-\frac{0.97}{T_{e}}}$ \\
\hline 14 & $e+O_{3} \rightarrow O_{2}^{-}+O$ & $8.81 \times 10^{-16} T_{e}^{-1.42} e^{-\frac{1.064}{T_{e}}}$ \\
\hline 15 & $O+O^{-} \rightarrow O_{2}+e$ & $3 \times 10^{-16} T_{e}^{-0.5}$ \\
\hline 16 & $\mathrm{O}^{-}+\mathrm{O}_{2}^{+} \rightarrow \mathrm{O}_{2}+\mathrm{O}$ & $1 \times 10^{-13}$ \\
\hline 17 & $O^{-}+O^{+} \rightarrow O+O$ & $1 \times 10^{-13}$ \\
\hline 18 & $O_{2}+O^{-} \rightarrow O_{3}+e$ & $5 \times 10^{-21}$ \\
\hline 19 & $O^{-}+O^{+} \rightarrow O+O^{*}$ & $2 \times 10^{-13}$ \\
\hline 20 & $O^{*}+O_{3} \rightarrow O_{2}+O_{2}$ & $1.2 \times 10^{-16}$ \\
\hline 21 & $O_{2}^{*}+O_{2} \rightarrow O+O_{3}$ & $2.95 \times 10^{-27}$ \\
\hline 22 & $\mathrm{O}^{-}+\mathrm{O}_{3} \rightarrow e+\mathrm{O}_{2}+\mathrm{O}_{2}$ & $3.01 \times 10^{-16} T_{g} 0.5 e^{-\frac{0}{T_{e}}}$ \\
\hline 23 & $\mathrm{O}+\mathrm{O}_{3}^{-} \rightarrow \mathrm{O}_{2}+\mathrm{O}_{2}^{-}$ & $3.2 \times 10^{-16}$ \\
\hline 24 & $O^{-}+O_{2}^{*} \rightarrow O_{3}+e$ & $3 \times 10^{-16}$ \\
\hline 25 & $\mathrm{O}_{2}{ }^{+}+\mathrm{O}_{2}{ }^{-} \rightarrow \mathrm{O}_{2}+\mathrm{O}_{2}{ }^{*}$ & $2 \times 10^{-13}$ \\
\hline 26 & $\mathrm{O}+\mathrm{O}_{3} \rightarrow \mathrm{O}_{2}+\mathrm{O}_{2}$ & $8 \times 10^{-18}$ \\
\hline 27 & $\mathrm{O}^{+}+\mathrm{O}_{3} \rightarrow \mathrm{O}_{2}+\mathrm{O}_{2}^{+}$ & $1 \times 10^{-16}$ \\
\hline
\end{tabular}




\begin{tabular}{|c|c|c|}
\hline 28 & $O^{-}+O_{2} \rightarrow e+O_{3}$ & $5 \times 10^{-21}$ \\
\hline 29 & $\mathrm{O}_{2}^{+}+\mathrm{O}_{3}^{-} \rightarrow \mathrm{O}_{2}^{*}+\mathrm{O}_{3}$ & $2 \times 10^{-13} T_{g}{ }^{-0.5} e^{-\frac{0}{T_{e}}}$ \\
\hline 30 & $\mathrm{O}^{+}+\mathrm{O}_{3} \rightarrow \mathrm{O}_{2}+\mathrm{O}_{2}^{+}$ & $1 \times 10^{-16}$ \\
\hline 31 & $\mathrm{O}^{-}+\mathrm{O}_{3} \rightarrow \mathrm{O}_{2}+\mathrm{O}_{2}^{-}$ & $1.02 \times 10^{-17} T_{g}^{0.5} e^{-\frac{0}{T_{e}}}$ \\
\hline 32 & $\mathrm{O}_{2}^{+}+\mathrm{O}_{3}^{-} \rightarrow \mathrm{O}+\mathrm{O}+\mathrm{O}_{3}$ & $1 \times 10^{-13}$ \\
\hline 33 & $\mathrm{O}_{2}^{+}+\mathrm{O}_{2}^{-} \rightarrow \mathrm{O}+\mathrm{O}+\mathrm{O}_{2}$ & $1 \times 10^{-13}$ \\
\hline 34 & $\mathrm{O}+\mathrm{O}_{3}^{-} \rightarrow \mathrm{O}_{2}+\mathrm{O}_{2}^{-}$ & $3.2 \times 10^{-16}$ \\
\hline 35 & $O^{-}+O_{2}^{+} \rightarrow O+O+O$ & $2 \times 10^{-13} T_{g}{ }^{-0.5} e^{-\frac{0}{T_{e}}}$ \\
\hline 36 & $\mathrm{O}_{2}^{+}+\mathrm{O}_{3}^{-} \rightarrow \mathrm{O}_{2}+\mathrm{O}_{3}$ & $1 \times 10^{-13}$ \\
\hline 37 & $\mathrm{O}^{+}+\mathrm{O}_{3}^{-} \rightarrow \mathrm{O}+\mathrm{O}_{3}$ & $1 \times 10^{-13}$ \\
\hline 38 & $\mathrm{O}_{2}^{+}+\mathrm{O}_{2}^{-} \rightarrow \mathrm{O}_{2}+\mathrm{O}_{2}$ & $1 \times 10^{-13}$ \\
\hline 39 & $\mathrm{O}^{+}+\mathrm{O}_{2}^{-} \rightarrow \mathrm{O}+\mathrm{O}_{2}$ & $1 \times 10^{-13}$ \\
\hline 40 & $\mathrm{O}+\mathrm{O}_{2}^{-} \rightarrow \mathrm{O}_{3}+e$ & $1.5 \times 10^{-16}$ \\
\hline 41 & $e+O_{2} \rightarrow O_{2}+e$ & $3.93 \times 10^{-14} T_{e}^{0.63} e^{\frac{0.019}{T_{e}}}$ \\
\hline 42 & $e+O \rightarrow O+e$ & $6.47 \times 10^{-14} T_{e}^{0.33} e^{-\frac{0.47}{T_{e}}}$ \\
\hline 43 & $O+\mathrm{O}_{2}^{+} \rightarrow \mathrm{O}_{2}+\mathrm{O}^{+}$ & $2 \times 10^{-17}$ \\
\hline 44 & $O+O^{+} \rightarrow O+O^{+}$ & $1 \times 10^{-15}$ \\
\hline 45 & $\mathrm{O}_{2}^{+}+\mathrm{O}_{2} \rightarrow \mathrm{O}_{2}^{+}+\mathrm{O}_{2}$ & $1 \times 10^{-15}$ \\
\hline
\end{tabular}

For this analysis, both symmetric charge exchange reactions and elastic collisions were omitted due to them contributing to matrix sparsity as well as them being crucial to 
discharge energy balance in an ideal modelling investigation.

Table 4 Changes in electron temperature and density, and species concentration for the reduction performed at 600 Torr.

\begin{tabular}{|c|c|c|c|}
\hline Species & Reduced $/ \mathrm{m}^{-3}$ & Full $/ \mathrm{m}^{-3}$ & Percentage Change \\
\hline $\mathrm{O}_{2}$ & $9.55 \mathrm{E}+22$ & $9.55 \mathrm{E}+22$ & $0 \%$ \\
\hline $\mathrm{O}^{*}$ & $7.75 \mathrm{E}+18$ & $8.36 \mathrm{E}+18$ & $7.29 \%$ \\
\hline $\mathrm{O}$ & $8.50 \mathrm{E}+21$ & $8.51 \mathrm{E}+21$ & $0.12 \%$ \\
\hline $\mathrm{O}_{2} *$ & $1.15 \mathrm{E}+25$ & $1.15 \mathrm{E}+25$ & $0 \%$ \\
\hline $\mathrm{O}^{\square}$ & $9.22 \mathrm{E}+17$ & $9.22 \mathrm{E}+17$ & $0 \%$ \\
\hline $\mathrm{O}_{2} \square$ & $1.30 \mathrm{E}+21$ & $1.30 \mathrm{E} 21$ & $0 \%$ \\
\hline $\mathrm{O}^{\square}$ & $1.71 \mathrm{E}+19$ & $1.21 \mathrm{E}+19$ & $41.32 \%$ \\
\hline $\mathrm{O}_{3}$ & $2.79 \mathrm{E}+21$ & $2.79 \mathrm{E}+21$ & $0 \%$ \\
\hline $\mathrm{O}_{2} \square$ & $1.68 \mathrm{E}+18$ & $1.68 \mathrm{E} 18$ & $0 \%$ \\
\hline $\mathrm{O}_{3} \square$ & $1.25 \mathrm{E}+16$ & $1.16 \mathrm{E}+16$ & $7.76 \%$ \\
\hline$T_{e}$ & $1.53 \mathrm{eV}$ & $1.53 \mathrm{eV}$ & $0 \%$ \\
\hline$n_{e}$ & $1.31 \mathrm{E}+21$ & $1.31 \mathrm{E}+21$ & $0 \%$ \\
\hline
\end{tabular}

Table 4 illustrates the changes in species concentration before and after reduction at 600 Torr. Being able to reduce a potentially complex set by about $25 \%$ without deviating greatly from the physics of the discharge is a significant advantage for $2 \mathrm{D}$ and $3 \mathrm{D}$ 
modelling. Table 4 suggests that the reduction eliminates unimportant pathways but maintains the overall behavior of the discharge.

Because this reduction was performed for a very high pressure, the same reduction is unlikely to work at lower pressures. To test this, the pressure was varied and species densities between the reduced and full sets were compared. Fig. 3 shows the results of numerical tests with pressures between 10 mTorr and 1000 Torr.

\section{Figure 3 here}

Figure 3 Comparison of various species for the full chemistry and a reduced chemistry generated at high pressure: (a) Electron Density, (b) Electron Temperature, (c) $\mathrm{O}_{3}$ Density, (d) $\mathrm{O}_{3}^{-}$Density, (e) $\mathrm{O}^{+}$Density, (f) O Density, (g) O* Density, and (h) $\mathrm{O}^{-}$ Density.

In essence, species whose participation in important reaction pathways is uncertain show a divergence in results between the reduced and full sets as the pressure is varied. This is illustrated particularly in the $\mathrm{O}^{*}$ comparison where there is a noticeable deviation in densities in the middle of the parameter space. It can also be seen that for the heavier species $\left(\mathrm{O}_{3}\right.$ and $\left.\mathrm{O}_{3}{ }^{-}\right)$, there is again noticeable deviation in the middle of the parameter space. This particular region represents a medium/high pressure region 
where there are many competing physical processes. It therefore becomes more uncertain which reaction pathways are dominant in these regions. Therefore, reduction via analysis must be undertaken again at those pressures. Since chemistry reduction must preserve the physical behavior of the plasma, the major plasma parameters such as electron density $n_{e}$ and electron temperature $T_{e}$ must not deviate significantly. It can be seen from the top panels in Figs. 3 that the values for the reduced and full chemistry overlap almost perfectly with very minor difference in the middle of the pressure parameter space for $T_{e}$.

Table 5. Reaction coefficients for the $\mathrm{O}_{2}$ chemistry set given in Table 3 used in the high pressure reduction. 


\begin{tabular}{|c|c|}
\hline & Coefficient $C_{i}$ \\
\hline 1 & $3.0449 \mathrm{E}-04$ \\
\hline 2 & $7.2378 \mathrm{E}-05$ \\
\hline 3 & $\sim 0$ \\
\hline 4 & $3.1437 \mathrm{E}-01$ \\
\hline 5 & $1.4749 \mathrm{E}-03$ \\
\hline 6 & $6.7164 \mathrm{E}-01$ \\
\hline 7 & $1.3739 \mathrm{E}-05$ \\
\hline 8 & $2.7901 \mathrm{E}-05$ \\
\hline 9 & 3.7209E-04 \\
\hline 10 & $\sim 0$ \\
\hline 11 & $\sim 0$ \\
\hline 12 & $3.1006 \mathrm{E}-07$ \\
\hline 13 & $8.5243 \mathrm{E}-02$ \\
\hline 14 & $1.8048 \mathrm{E}-02$ \\
\hline 15 & $\sim 0$ \\
\hline 16 & $2.3749 \mathrm{E}-03$ \\
\hline 17 & $2.2873 \mathrm{E}-05$ \\
\hline 18 & $\sim 0$ \\
\hline 19 & $\sim 0$ \\
\hline 20 & $1.1524 \mathrm{E}-04$ \\
\hline 21 & $\sim 0$ \\
\hline 22 & $8.1073 \mathrm{E}-04$ \\
\hline 23 & $\sim 0$ \\
\hline 24 & $1.3040 \mathrm{E}-01$ \\
\hline 25 & $1.7875 \mathrm{E}-02$ \\
\hline 26 & $7.8223 \mathrm{E}-03$ \\
\hline 27 & $1.3930 \mathrm{E}-04$ \\
\hline 28 & $\sim 0$ \\
\hline 29 & $5.5463 \mathrm{E}-06$ \\
\hline 30 & $1.3930 \mathrm{E}-04$ \\
\hline 31 & $\sim 0$ \\
\hline 32 & 7.4561E-05 \\
\hline 33 & $2.2190 \mathrm{E}-03$ \\
\hline 34 & $\sim 0$ \\
\hline 35 & $2.0690 \mathrm{E}-04$ \\
\hline
\end{tabular}




\begin{tabular}{|c|c|}
\hline 36 & $2.7901 \mathrm{E}-05$ \\
\hline 37 & $2.7115 \mathrm{E}-07$ \\
\hline 38 & $8.9597 \mathrm{E}-03$ \\
\hline 39 & $4.1802 \mathrm{E}-05$ \\
\hline 40 & $3.2198 \mathrm{E}-05$ \\
\hline
\end{tabular}

Table 5 gives the reaction coefficients for the $\mathrm{O}_{2}$ chemistry set determined by the sensitivity analysis. In the global system, the most important reactions (to within $\frac{1}{1000}$ ) that control species concentrations are illustrated in Fig. 4.

\section{Figure 4 here}

Figure 4. Coefficients of important pathways within the $\mathrm{O}_{2}$ global system.

The coefficient of zero for reaction 3, DEA of $\mathrm{O}_{2}$ via e $+\mathrm{O}_{2} \rightarrow \mathrm{O}+\mathrm{O}^{-}$, is misleading. This reaction pathway is the primary source of $\mathrm{O}^{-}$ions, yet either its global presence is insensitive, or the method wrongly considers it negligible to the system as a whole. Local sensitivity of the $\mathrm{O}^{-}$ion concentration however identifies this pathway as important to the concentration of $\mathrm{O}^{-}$, see Fig. 5.

\section{Figure 5 here}

Figure 5. Coefficients of dominant pathways within the $\mathrm{O} \square$ local system.

What the method does not recognize, however, is that the pathway of e $+\mathrm{O}_{3} \rightarrow \mathrm{O}_{2}+$ $\mathrm{O}^{-}$depends directly on the production of $\mathrm{O}^{-}$as the formation of $\mathrm{O}_{3}$ in the system is 
dominated by associative ionization: $\mathrm{O}_{2}+\mathrm{O}^{-} \rightarrow \mathrm{O}_{3}+$ e.

\subsection{2 $\mathrm{CF}_{4} / \mathrm{O}_{2} / \mathrm{N}_{2} / \mathrm{H}_{2}$ chemistry}

Due to the size of the $\mathrm{CF}_{4} / \mathrm{O}_{2} / \mathrm{N}_{2} / \mathrm{H}_{2}$ chemistry and the fact that it was carried out by hand, 3 local systems of important species were created; $\mathrm{F}, \mathrm{F}^{+}$and $\mathrm{O}$. This analysis was attempted by modelling the discharge at 10 mTorr. Using reduction via numerical sensitivity analysis reduces the reaction set was reduced from 396 to 71 reactions, and the species involved halved from 52 to 26 .

Figure 6 here

Figure 6 Dominant pathways of $\mathrm{F}$ production and loss in the low pressure $\mathrm{CF}_{4} / \mathrm{O}_{2} / \mathrm{N}_{2} / \mathrm{H}_{2}$ chemistry.

Again in concordance with the plasma conditions, the main loss process of atomic $\mathrm{F}$ is its subsequent ionization mechanism. Sources for F include the electron impact dissociation of $\mathrm{CF}_{\mathrm{x}}$ species, see Fig. 6 .

\section{Figure 7 here}

Figure 7. Dominant pathways for $\mathrm{F}^{+}$production and loss in the $\mathrm{CF}_{4} / \mathrm{O}_{2} / \mathrm{N}_{2} / \mathrm{H}_{2}$ chemistry.

Figure 7 gives the important mechanisms for gas-phase $\mathrm{F}^{+}$production and loss. The fact that gas phase loss processes were insensitive, it suggests that the main loss process for $\mathrm{F}^{+}$involves recombination on nearby surfaces via the Bohm process. This is actually 
in accordance to the 10 mTorr plasma conditions and helps to confirm our numerical analysis in chemistry reduction.

\section{Figure 8 here}

Figure 8. Dominant pathways of $\mathrm{O}$ production and loss.

Figure 8 shows that the main source of atomic oxygen is from the dissociation of the $\mathrm{O}_{2}$ feed gas whilst the main loss process is the resultant ionization of the atom. Note that the dissociation of $\mathrm{OH}$ is eventually ignored in the final reduction due to the $\mathrm{OH}$ density being low and its dissociation not being an important intermediate step for the rest of the discharge.

\section{Figure 9 here}

Figure 9. Comparison of various species for the full chemistry and a reduced chemistry generated for $\mathrm{CF}_{4} / \mathrm{O}_{2} / \mathrm{N}_{2} / \mathrm{H}_{2}$ at low pressure for the (a) Electron Density, (b) Electron Temperature, (c) F Density, and (d) O Density.

Figure 9 shows the variation of $T_{e}, n_{e}$ and the concentration of $\mathrm{F}$ and $\mathrm{O}$ with pressure as predicted with the full and reduced (low pressure) chemistry. It can be seen that the plasma parameters agree very closely in the low pressure region. Divergence begins at high pressure. The two local systems used for reduction were $\mathrm{F}$ and $\mathrm{O}$. F being the main etchant in this chemistry means that the uncertainty regarding its pathways is very low and the main sources of its production are prevalent at all pressures. Divergence of $\mathrm{O}$ on the other hand can be seen as the pressure is increased to where the discharge 
behavior begins to exhibit more varied processes.

\section{Figure 10 here}

Figure 10 Comparison of various species for the full chemistry and a reduced chemistry generated for $\mathrm{CF}_{4} / \mathrm{O}_{2} / \mathrm{N}_{2} / \mathrm{H}_{2}$ at low pressure for the (a) $\mathrm{H}$ Density, (b) $\mathrm{N}$ Density, (c) $\mathrm{F}^{-}$Density, and (d) $\mathrm{CF}_{3}{ }^{+}$Density.

Figure 10 shows some species evolutions whose local systems were not investigated and it can be seen that divergence from the low pressure densities is very noticeable especially in the case of $\mathrm{CF}_{3}^{+}-$this is an example of perturbation of another local system.

Close agreement is expected from $1-30 \mathrm{mTorr}$ as sensitivity analysis at $10 \mathrm{mTorr}$ is based on a very low pressure regime. It can be seen however that using the same reduced set for higher pressure begins to yield diverged results which do not verily agree with each other and this is expected as the plasma becomes more collisions and heavy-particle gas phase collisions (some of which were removed) become a lot more dominant.

Table 6 shows the densities and electron parameters for the full and reduced $\mathrm{CF}_{4} / \mathrm{O}_{2} / \mathrm{N}_{2} / \mathrm{H}_{2}$ chemistry obtained using our numerical sensitivity procedure. The density changes for $\mathrm{CF}_{2}{ }^{+}$and $\mathrm{CF}_{3}{ }^{+}$are caused by not taking into account other local

systems. A way around this would be global analysis, but the side effect of this is having certain important reaction pathways appear insensitive as the densities of these ions are about three orders of magnitude smaller than the electron density. These larger 
relative changes are not expected to influence the plasma as a whole. The 71 reaction rates that constitute the reduced, $1-30 \mathrm{mTorr} \mathrm{CF}_{4} / \mathrm{O}_{2} / \mathrm{N}_{2} / \mathrm{H}_{2}$ are available from QDB.

Table 6. Densities and electron energies for the full and reduced $\mathrm{CF}_{4} / \mathrm{O}_{2} / \mathrm{N}_{2} / \mathrm{H}_{2}$ chemistry obtained using numerical sensitivity analysis.

\begin{tabular}{|c|c|c|c|}
\hline Species & Reduced Set & Full Set & $\begin{array}{c}\text { Percentage } \\
\text { Change }\end{array}$ \\
\hline $\mathrm{H}_{2}$ & $6.04 \mathrm{E}+17 \mathrm{~m}^{-3}$ & $5.74 \mathrm{E}+17 \mathrm{~m}^{-3}$ & 5.27 \\
\hline $\mathrm{H}$ & $2.34 \mathrm{E}+18 \mathrm{~m}^{-3}$ & $2.21 \mathrm{E}+18 \mathrm{~m}^{-3}$ & 5.91 \\
\hline$\overline{\mathrm{H}^{+}}$ & $5.72 \mathrm{E}+15 \mathrm{~m}^{-3}$ & $5.56 \mathrm{E}+15 \mathrm{~m}^{-3}$ & 2.79 \\
\hline $\mathrm{H}^{-}$ & $6.25 \mathrm{E}+15 \mathrm{~m}^{-3}$ & $4.04 \mathrm{E}+15 \mathrm{~m}^{-3}$ & 54.53 \\
\hline$\overline{\mathrm{O}_{2}}$ & $1.81 \mathrm{E}+20 \mathrm{~m}^{-3}$ & $1.78 \mathrm{E}+20 \mathrm{~m}^{-3}$ & 1.72 \\
\hline $\mathrm{O}^{-}$ & $4.09 \mathrm{E}+16 \mathrm{~m}^{-3}$ & $2.65 \mathrm{E}+16 \mathrm{~m}^{-3}$ & 54.34 \\
\hline$\overline{\mathrm{O}}$ & $4.13 \mathrm{E}+19 \mathrm{~m}^{-3}$ & $3.77 \mathrm{E}+19 \mathrm{~m}^{-3}$ & 9.46 \\
\hline $\mathrm{O}_{2}{ }^{+}$ & $2.64 \mathrm{E}+18 \mathrm{~m}^{-3}$ & $2.65 \mathrm{E}+18 \mathrm{~m}^{-3}$ & 0.27 \\
\hline$\overline{\mathrm{O}^{+}}$ & $5.91 \mathrm{E}+17 \mathrm{~m}^{-3}$ & $5.49 \mathrm{E}+17 \mathrm{~m}^{-3}$ & 7.65 \\
\hline $\mathrm{N}_{2}$ & $3.00 \mathrm{E}+19 \mathrm{~m}^{-3}$ & $2.08 \mathrm{E}+19 \mathrm{~m}^{-3}$ & 44.25 \\
\hline $\mathrm{N}$ & $7.66 \mathrm{E}+18 \mathrm{~m}^{-3}$ & $1.66 \mathrm{E}+19 \mathrm{~m}^{-3}$ & 53.81 \\
\hline $\mathrm{N}_{2}^{+}$ & $2.14 \mathrm{E}+17 \mathrm{~m}^{-3}$ & $1.58 \mathrm{E}+17 \mathrm{~m}^{-3}$ & 0.01 \\
\hline $\mathrm{N}^{+}$ & $3.19 \mathrm{E}+16 \mathrm{~m}^{-3}$ & $7.75 \mathrm{E}+16 \mathrm{~m}^{-3}$ & 58.82 \\
\hline $\mathrm{CF}_{4}$ & $1.35 \mathrm{E}+17 \mathrm{~m}^{-3}$ & $1.35+17 \mathrm{~m}^{-3}$ & 0.51 \\
\hline $\mathrm{F}$ & $1.08 \mathrm{E}+16 \mathrm{~m}^{-3}$ & $1.56 \mathrm{E}+17 \mathrm{~m}^{-3}$ & 30.49 \\
\hline$\overline{\mathrm{F}^{-}}$ & $9.26 \mathrm{E}+13 \mathrm{~m}^{-3}$ & $8.31 \mathrm{E}+13 \mathrm{~m}^{-3}$ & 11.43 \\
\hline
\end{tabular}




\begin{tabular}{|c|c|c|c|}
\hline $\mathrm{CF}_{3}$ & $6.05 \mathrm{E}+16 \mathrm{~m}^{-3}$ & $4.87 \mathrm{E}+16 \mathrm{~m}^{-3}$ & 24.31 \\
\hline $\mathrm{CF}_{2}$ & $2.31 \mathrm{E}+16 \mathrm{~m}^{-3}$ & $2.45 \mathrm{E}+16 \mathrm{~m}^{-3}$ & 14.05 \\
\hline $\mathrm{CF}_{3}^{+}$ & $4.35 \mathrm{E}+15 \mathrm{~m}^{-3}$ & $1.23 \mathrm{E}+15 \mathrm{~m}^{-3}$ & 252.58 \\
\hline $\mathrm{F}^{+}$ & $3.51 \mathrm{E}+14 \mathrm{~m}^{-3}$ & $5.09 \mathrm{E}+14 \mathrm{~m}^{-3}$ & 31.05 \\
\hline $\mathrm{CF}_{2}^{+}$ & $1.66 \mathrm{E}+15 \mathrm{~m}^{-3}$ & $5.38 \mathrm{E}+14 \mathrm{~m}^{-3}$ & 209.40 \\
\hline $\mathrm{CF}^{+}$ & $7.16 \mathrm{E}+14 \mathrm{~m}^{-3}$ & $5.53 \mathrm{E}+14 \mathrm{~m}^{-3}$ & 29.60 \\
\hline $\mathrm{CF}$ & $1.07 \mathrm{E}+16 \mathrm{~m}^{-3}$ & $7.73 \mathrm{E}+15 \mathrm{~m}^{-3}$ & 92.09 \\
\hline $\mathrm{HF}$ & $5.19 \mathrm{E}+16 \mathrm{~m}^{-3}$ & $5.31 \mathrm{E}+16 \mathrm{~m}^{-3}$ & 2.13 \\
\hline $\mathrm{HF}^{+}$ & $1.27 \mathrm{E}+14 \mathrm{~m}^{-3}$ & $1.34 \mathrm{E}+14 \mathrm{~m}^{-3}$ & 5.3 \\
\hline $\mathrm{T}_{\mathrm{e}}$ & $3.56 \mathrm{eV}$ & $3.60 \mathrm{eV}$ & 1.11 \\
\hline $\mathrm{n}_{\mathrm{e}}$ & $3.45 \mathrm{E}+18 \mathrm{~m}^{-3}$ & $3.42 \mathrm{E}+18 \mathrm{~m}^{-3}$ & 0.86 \\
\hline
\end{tabular}

Table 6 retains more of the full chemical species ( 25 species) when compared to table 2 which contains 21 species. This retention is a result of our method of analysis which identifies dominant reaction pathways without resorting to sweeping generalizations as in table 2. Table 2 however does illustrate that chemistry set reduction can occur with sensible argument and knowledge of the plasma physics, this is shown by the largest percentage change being $91.52 \%$ in $\mathrm{H}_{2}$ - which developed due to the removal of $\mathrm{H}_{2}$ losses from the set. The largest changes in table 6 are seen to be in species whose densities are a lot smaller than the electron density which therefore makes it more uncertain their participation within the chemistry set. It can be seen however that the behavior of the plasma remains largely unchanged due to the near identical values of electron density and temperature - which are crucial plasma parameters. 


\section{Conclusion}

Using 0D modeling in conjunction with validated data from QDB [7] enables the rapid study of simple to complex chemistries for process development. However, process development and general innovation follows a workflow that is often constrained by the understanding and complexity of the chemistry of the species involved. We show that by considering the appropriate pressure regimes, power disposition and other general considerations, the chemistry needed for such studies can, in favorable cases, be greatly simplified. The simplified or reduced chemistries are much more suitable for reactor models performed in two or three dimensions.

Using stoichiometric sensitivity analysis as a way to reduce chemistries by determining the important reaction pathways without deviating from the physical discharge was demonstrated here. Turner [34] commented that investigating uncertainty and error to reduce complex chemistry is possible, but not the best way. A more systematic approach involving dimension reduction based upon principal component analysis is provided by Perenboom et al. [35]. Indeed our results show that focusing on only uncertainty can become misleading as demonstrated with the $\mathrm{O}_{2}$ dissociation pathway. However, the method displayed here actually uses stoichiometric coefficients to evaluate production and losses. In the case of insensitive reaction pathways, these are more easily seen in a local system rather than visualizing the system as a whole. This was again seen with the $\mathrm{O}_{2}$ DEA pathway and the increasing divergence of $\mathrm{F}^{-} / \mathrm{CF}_{3}{ }^{+}$in the $\mathrm{CF}_{4} / \mathrm{N}_{2} / \mathrm{O}_{2} / \mathrm{H}_{2}$ species when the gas pressure was increased. 
Comparisons can be made with Markosyan et al. [13] reporting the use of their PumpKin tool. Markosyn uses the example of $\mathrm{O}_{3}{ }^{-}$destruction to suggest that the reaction pathway $\mathrm{O}_{3}^{-}+\mathrm{O} \rightarrow \mathrm{O}_{2}+\mathrm{O}_{2}+$ e was responsible for $94 \%$ of the total $\mathrm{O}_{3}{ }^{-}$ destruction. Our analysis at the high pressure regime however suggests that $\mathrm{O}_{3}{ }^{-}$ destruction is split (52\% and $42 \%$ respectively) between $\mathrm{O}_{2}{ }^{+}+\mathrm{O}_{3}{ }^{-} \rightarrow \mathrm{O}+\mathrm{O}+\mathrm{O}_{3}$ and $\mathrm{O}_{2}{ }^{+}+\mathrm{O}_{3}{ }^{-} \rightarrow \mathrm{O}_{2}+\mathrm{O}_{3}$. Identification of dominant pathways is therefore dependent on system pressure and power deposition in the $0 \mathrm{D}$ reactor. It is the current aim to improve this method for the purposes of dynamic chemistry assembling and reduction.

\section{Acknowledgments}

We thank Trymax for helpful discussions and sharing information about their reactor which prompted an investigation into this complex chemistry. This project received funding from the Electronic Component Systems for European Leadership Joint Undertaking under the Powerbase project, grant agreement No 662133. This Joint Undertaking receives support from the European Union's Horizon 2020 research and innovation programme and Austria, Belgium, Germany, Italy, Netherlands, Norway, Slovakia, Spain, United Kingdom.

\section{References}

[1] Bartschat K and Kushner M J 2016, Proc. Nat. Acad. Sci., 113, 7026-34

[2] Adamovich I et al. 2017, J. Phys. D: Appl. Phys., 50, 323001

[3] Yoon J S et al. 2010, AIP Conference Proceedings 1344, 197-203 
[4] Wakelam V et al. 2015 Astrophys. J. Suppl., 217, 20

[5] Celiberto R et al. 2016 Plasma Sources Sci. Technol. 26, 033004

[6] Pitchford L C et al. 2017, Plasma Proc. Polymers, 14, 1600098

[7] Tennyson J et al. 2017, Plasma Sources Sci. Technol, 26, 055014

[8] Song M-Y et al. 2015, J. Phys. Chem. Ref. Data, 44, 023101

[9] Song M-Y et al. 2017, J. Phys. Chem. Ref. Data, 46, 013106

[10] Song M-Y et al. 2017, J. Phys. Chem. Ref. Data, 46, 043104

[11] COMSOL Multiphyiscs Software, see www.comsol.com/comsol-multiphysics

[12] Holdship J et al. 2018, Astrophys. J. 116, 866

[13] Markosyan, A.H et al. 2014 Comp. Phys. Comms., 185, 2697-2702

[14] Kokkoris M et al. E 2008, J. Phys D: Appl. Phys., 41, 195211

[15] Kokkoris G et al. 2009, J. Phys D: Appl. 42, 055209

[16] Turner M M 2016, Plasma Sources Sci. Technol. 25, 015003

[17] Lam S H 1995, "Reduced Chemistry Modelling and Sensitivity Analysis", Mechanical and Aerospace Engineering, Princeton University, Phys., 42, 055209.

https://www.researchgate.net/publication/2504582_Reduced_Chemistry_Modeling_a nd_Sensitivity_Analysis

[18] Fracassi F et al. 1995, J. Vac. Sci. Technol., A 13, 335.

[19] Matsuo, P J et al, 1997. J. Vac. Sci. Technol., 15, 1801-1813

[20] Premachandran V 1990, Appl. Phys. Letts. 57 678-679

[21] Christophorou L G et al. 1996, J. Phys. Chem. Ref. Data 25, 1341

[22] Song S-H and Kushner M J 2012, Plasma Sources Sci. Technol. 21, 055028

[23] Hayash M 1979, J. Phys. Colloques 40, C2-661-662

[24] Phelps A V 1975 Compilation of Electron Cross Sections (unpublished). 
[25] Hayashi M 1990, NATO ASI series B, 220, 333-340 (Plenum, New York).

[26] Stief L J 1970, J. Chem. Phys. 52, 4841

[27] Bonham R A 1994, Jap. J. Appl. Phys. 33, 4157

[28] Vasenkov A V et al. 2004, J. Vacuum Sci. Technol. A 22, 511

[29] Bose D et al. 2003, Plasma Sources Sci. Technol. 12, 225-234

[30] Yang W et al. 2018, Plasma Sources Sci. Technol. 27, 075006

[31] Brian J 1980, Phys. Rep. 186, 215-248

[32] Itikawa Y 2009, J. Phys. Chem. Ref. Data 38, 1

[33] Kossyi I A et al.. 1992, Plasma Sources Sci. Technol. 1, 207-220

[34] Turner M M 2016, Plasma Source Sci. Technol. 24, 035027

[35] Peerenboom K et al, 2015, Plasma Sources Sci. Technol 24, 025004 